\title{
Diagnostic testing and analysis of Independent ignition system based on the Volkswagen 1.8T engine
}

\author{
Fang Wen ${ }^{1, a}$, Zhou Linfu ${ }^{2, b}$ \\ ${ }^{1}$ Sichuan Vocational and Technical College of Communications,china \\ ${ }^{2}$ Sichuan Vocational and Technical College of Communications,china \\ ascjyfw@163.com, ${ }^{\mathrm{b}}$ scjyzlf@126.com
}

\begin{abstract}
According to fault diversity of independent electronic ignition system based on the Volkswagen 1.8T engine, analyzed Sagitar circuit structure of single-cylinder independent ignition system. By the Volkswagen detector 6150 and BOSCH FSA740 analyzer equipment, used diagnostic methods of Volkswagen independent ignition system fault code list, engine block, secondary ignition waveform testing, then tested and analyzed fault of the too small spark plug gap , circuit breaker of the ignition coil power supply line, input signal line and signal ground line, two cylinder signal line exchange etc.The test and analysis results showed fault of independent electronic ignition system effectively.
\end{abstract}

Keywords: FAW-Volkswagen; independent ignition system; diagnosis; testing

The automobile gasoline engine has the direction development of high speed, high compression ratio, low fuel consumption and low emissions, the traditional ignition system can not adapted to the requirements. Modern ignition system improve the ignition energy by independent ignition coil. The spark plug produce enough energy to meet the needs of modern engine arcing conditions. This paper test and analysis independent ignition system based on Volkswagen Sagitar for technical troubleshooting staff.

\section{Independent ignition system structure of 1.8T Sagitar}

Volkswagen Sagitar FSI independent electronic ignition system is assigned an ignition coil ( N70, N127, N291, N292) in per-cylinder(1,2,3,4). A independent ignition coils close to a spark plug located on the cylinder head. Each ignition coil primary winding are accepted ignition signal according to the sequence of 1-3-4-2 distribution by the engine control unit J623. The engine speed sensor G28 and camshaft Holzer sensor G40 to realize precision ignition by monitoring the cylinder compression, as shown in figure 1. Due to the cancellation of the distributor and the high-voltage wire, independent electronic ignition system energy conduction and leakage loss minimization. It does not interfere with the knock sensor system that there is not distributor rotating mechanical vibration; it dramatically reduces the electromagnetic interference that there is external metal inclusions for each cylinder ignition coil and spark plug assembly together; it make full use of the space that spark ignition coil assembly mounted on the middle of DOHC; it does not adjustment the ignition angle because of the control unit J623 determines. 


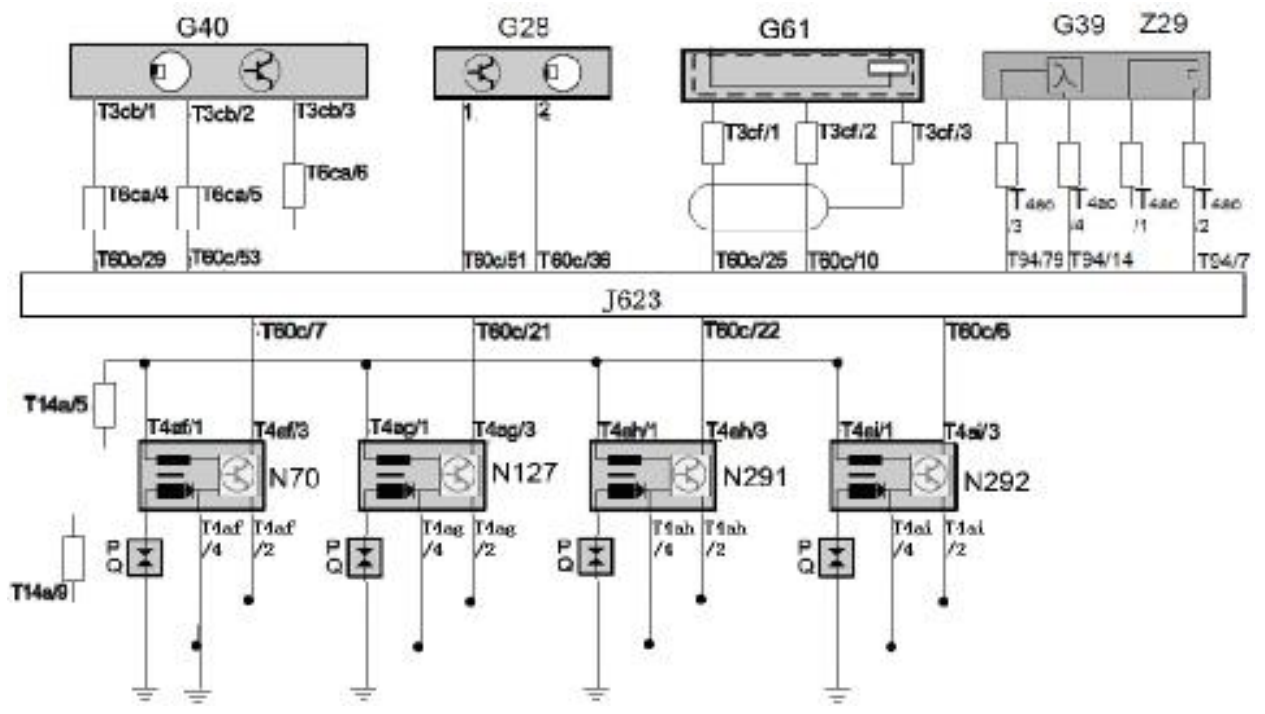

Fig.1 Independent ignition system structure of 1.8T Sagitar

\section{Independent ignition system diagnosis method of 1.8T Sagitar}

Volkswagen Sagitar ignition system electrical components requires at least $11.5 \mathrm{~V}$ voltage for work normally. To avoid personal injury or electrical components damage, it should connect or disconnect the ignition coil cable for detection when ignition switch off.

\section{fault code}

The engine control unit will be detected and stored fault memory If the independent electronic ignition system failure. It check and erase the fault codes by the Volkswagen dedicated tester 6150 or VAS5052 when power off. Volkswagen independent ignition system fault code as shown in table 1 .

table 1 Volkswagen independent ignition system fault code list

\begin{tabular}{|l|l|l|l|l|l|}
\hline SAE & VAG & fault code explain & SAE & VAG & fault code explain \\
\hline P0300 & 16684 & $\begin{array}{l}\text { Random / multi cylinder misfire } \\
\text { detection }\end{array}$ & P1358 & 17766 & 2 cylinder ignition circuit: open \\
\hline P0301 & 16685 & 1 cylinder misfire detection & P1359 & 17767 & $\begin{array}{l}2 \text { cylinder ignition circuit: short } \\
\text { circuit to positive }\end{array}$ \\
\hline P0302 & 16686 & 2 cylinder misfire detection & P1360 & 17768 & $\begin{array}{l}2 \text { cylinder ignition circuit: short } \\
\text { circuit to ground }\end{array}$ \\
\hline P0303 & 16687 & 3 cylinder misfire detection & P1361 & 17769 & 3 cylinder ignition circuit: open \\
\hline P0304 & 16688 & 4 cylinder misfire detection & P1362 & 17770 & $\begin{array}{l}3 \text { cylinder ignition circuit: short } \\
\text { circuit to positive }\end{array}$ \\
\hline P1355 & 17763 & 1 cylinder ignition circuit: open & P1363 & 17771 & $\begin{array}{l}3 \text { cylinder ignition circuit: short } \\
\text { circuit to ground }\end{array}$ \\
\hline P1356 & 17764 & $\begin{array}{l}1 \text { cylinder ignition circuit: short } \\
\text { circuit to positive }\end{array}$ & P1364 & 17772 & 4 cylinder ignition circuit: open \\
\hline P1357 & 17765 & $\begin{array}{l}1 \text { cylinder ignition circuit: short } \\
\text { circuit to ground }\end{array}$ & P1365 & 17773 & $\begin{array}{l}4 \text { cylinder ignition circuit: short } \\
\text { circuit to positive }\end{array}$ \\
\hline & & & P1366 & 17774 & $\begin{array}{l}4 \text { cylinder ignition circuit: short } \\
\text { circuit to ground }\end{array}$ \\
\hline
\end{tabular}

\section{Data block}

Data blocks may be provided with timely data engine operating condition, the correct analysis of data blocks represent a diagnostic capability. It analysis of its causes with reference to repair manual for abnormal value data. For example, a cylinder ignition coil operating failure, the cylinder will cause a misfire phenomenon. it will read cylinder misfire counts by tester 6150 or VAS5052 in 14,15 and16 data blocks display group, according to the datas for fault diagnosis. Data block display data of each cylinder misfire number sum in the third line of 14 group; Data block display data of 1,2,3 cylinder misfire counts in 1,2,3 lines of 15 group respectively; measuring data blocks show the fourth cylinder misfire counts in 1 line of 16 group. Misfire counter will begin counting 
after engine operate stablely. Volkswagen independent ignition system data block as shown in table 2 .

table 2 Engine ignition data block and basic set

\begin{tabular}{|l|l|l|l|}
\hline $\mathbf{0 0 3}$ & idle speed & & \\
\hline engine speed & the amount of intake air & throttle opening degree (G187) & Ignition advance angle \\
\hline $700 \sim 860 \mathrm{rpm}$ & $2.0 \sim 4.5 \mathrm{~g} / \mathrm{s}$ & $0.2 \sim 4.0 \%$ & $3 \sim 6^{\circ} \mathrm{BTDC}$ \\
\hline $\mathbf{0 1 0}$ & idle speed & & \\
\hline engine speed & engine load & throttle opening degree (G187) & Ignition advance angle \\
\hline $700 \sim 860 \mathrm{rpm}$ & $13.5 \sim 150 \%$ & $7 \%$ & $3 \sim 6^{\circ} \mathrm{BTDC}$ \\
\hline $\mathbf{0 1 1}$ & idle speed & & \\
\hline engine speed & coolant temperature & Intake air temperature & Ignition advance angle \\
\hline $700 \sim 860 \mathrm{rpm}$ & $80 \sim 105^{\circ} \mathrm{C}$ & $-48 \sim 105^{\circ} \mathrm{C}$ & $3 \sim 6^{\circ} \mathrm{BTDC}$ \\
\hline $\mathbf{0 1 4}$ & driving & misfire recognition & \\
\hline engine speed & engine load & The total misfire number & misfire recognition \\
\hline $700 \sim 6600$ rpm & $13 \sim 45 \%$ & $0 \sim 5$ & active/blocked \\
\hline $\mathbf{0 1 5}$ & driving & $\begin{array}{l}\mathbf{1} \mathbf{3} \text { cylinder misfire } \\
\text { recognition }\end{array}$ & \\
\hline $\begin{array}{l}1 \text { cylinder misfire } \\
\text { number }\end{array}$ & 2 cylinder misfire number & 3 cylinder misfire number & misfire recognition \\
\hline 0 & 0 & 0 & active/blocked \\
\hline $\mathbf{0 1 6}$ & driving & $\mathbf{4 ~ c y l i n d e r ~ m i s f i r e ~ r e c o g n i t i o n ~}$ & \\
\hline $\begin{array}{l}4 \text { cylinder misfire } \\
\text { number }\end{array}$ & & & misfire recognition \\
\hline 0 & & & active/blocked \\
\hline
\end{tabular}

\section{Waveform testing}

The method of read fault code and the data block can not apply to all electronic fault. For the independent electronic ignition system, multimeter and oscilloscope is a more effective means. Electronic ignition system components have a certain resistance value range,and there is a voltage output signal and output pulse waveform range. Therefore the multimeter is used to measure the resistance or the output voltage, oscilloscope test the output voltage waveform, it may be more accurate to judge the components or circuit. Primary signal voltage and secondary arcing voltage waveform test connection method as shown in figure 2.

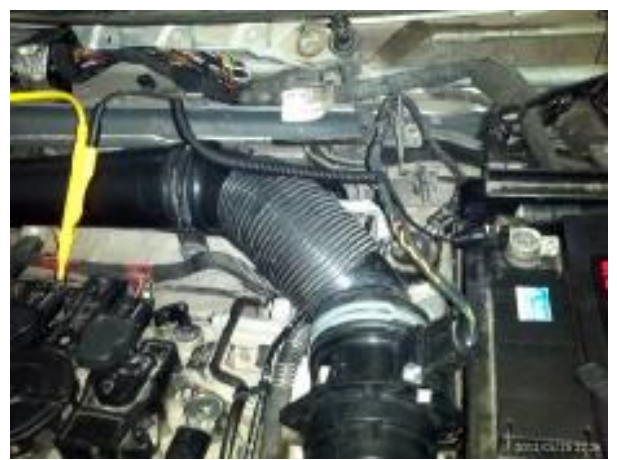

a)Primary signal voltage

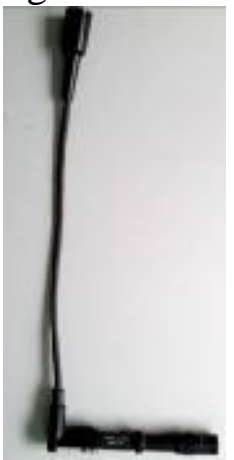

b)High voltage test cable

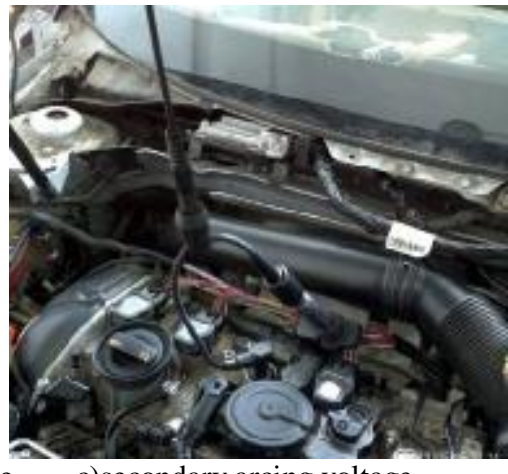

c)secondary arcing voltage

Fig. 2 Primary signal voltage and secondary arcing voltage test connection method

\section{Independent ignition system of the Volkswagen 1.8T engine diagnosis test and analysis}

The secondary waveform of Independent electronic ignition system can provide combustion state of each cylinder. The secondary ignition waveform was significantly affected by the different engine, fuel system and ignition conditions. Different parts of the waveform can indicate operation condition of particular cylinder related to components and the system. For diagnostic testing, the waveform can observe different between data secondary signal and standard secondary data signal by BOSCH FSA740 engine analyzer.

Independent ignition system normal waveform testing 
From the Figure 3, the spark plug gap between the center electrode and the ground electrode arcing sparks when the ignition voltage of $10 \mathrm{kv}$. At the same time, the secondary voltage suddenly dropped to the lower combustion voltage $1 \mathrm{kV}$. When the memory is provided with energy less than a specific value, spark stops arc. Voltage signal curve depends largely on the use of oscilloscope. The general rule is: the higher resolution, more clearly signal display.

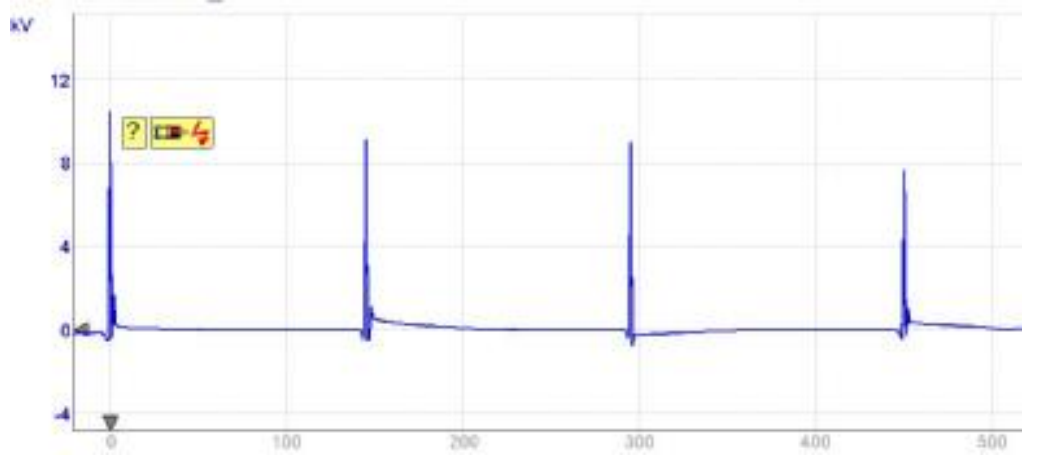

Fig. 3 single cylinder the secondary ignition coil normal waveform

\section{too small Spark plug gap fault diagnosis and waveform testing}

If the 3 cylinder spark plug gap is too small, it can read fault code P0303,3 cylinder detected misfire ( static ) by the 6150 or VAS5052. Data block 14,15,16 group shows total of 134 times, 3 cylinder misfire of 134 times in stable misfire condition. The secondary wave testing for 3 cylinder, from the figure 4 , ignition cycle is $177.4^{\circ}\left(180^{\circ}\right.$ - ignition advance angle of $\left.2.6^{\circ}\right)$. The secondary wave ignition peak value is about $3.8 \mathrm{KV}$, it was significantly lower than the secondary wave ignition normal voltage of $10 \mathrm{KV}$. The secondary ignition voltage is too low, the spark plug gap is too small.

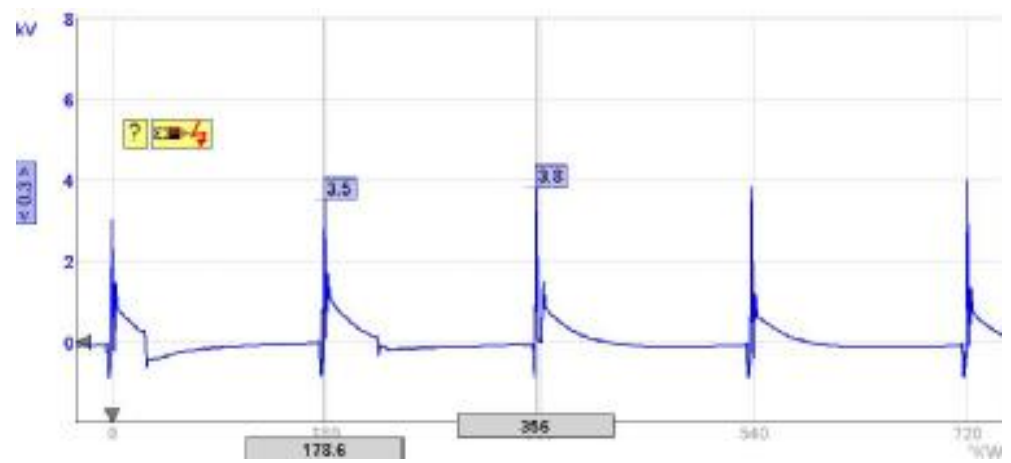

Fig. 4 the secondary ignition oscillogram of too small spark plug gap

ignition coil power supply line open circuit fault diagnosis and waveform testing

If ignition coil N70 T4af/1 line is open, we can be observed trembling on engine block. It read the fault code P0301,1 cylinder detected misfire ( static ). Data block 14,15,16 group shows total of 47 times, and 1cylinder misfire of 47 times in stable misfire condition. From the Figure 5, 1 cylinder secondary waveform is $0 \mathrm{KV}$ stablely, there is not ignition peak voltage generation.

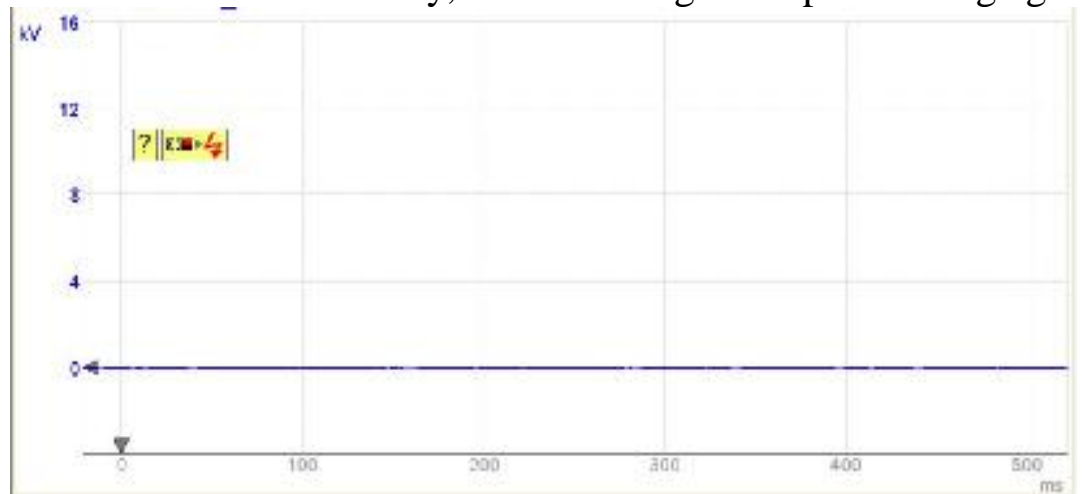

Fig.5 the secondary ignition oscillogram of ignition coil power supply line open circuit fault ignition coil input signal line and signal ground line circuit breaker fault diagnosis and waveform testing 
If ignition coil N70 T4af/2 (signal input line) and T4af/3( signal ground line) are open, we can be observed trembling on engine block. It read the fault code P2301, P1355"; ignition coil A" control circuit of high, 1cylinder ignition control circuit breaker. Data block 14,15,16 group shows total of 181 times, and 1cylinder misfire of 181 times in stable misfire condition; data block 11 group display ignition angle $15^{\circ}$ ( standards $6-12^{\circ}$ ). From the Figure 6,1 cylinder secondary waveform is $0 \mathrm{KV}$ stablely, there is not ignition peak voltage generation.

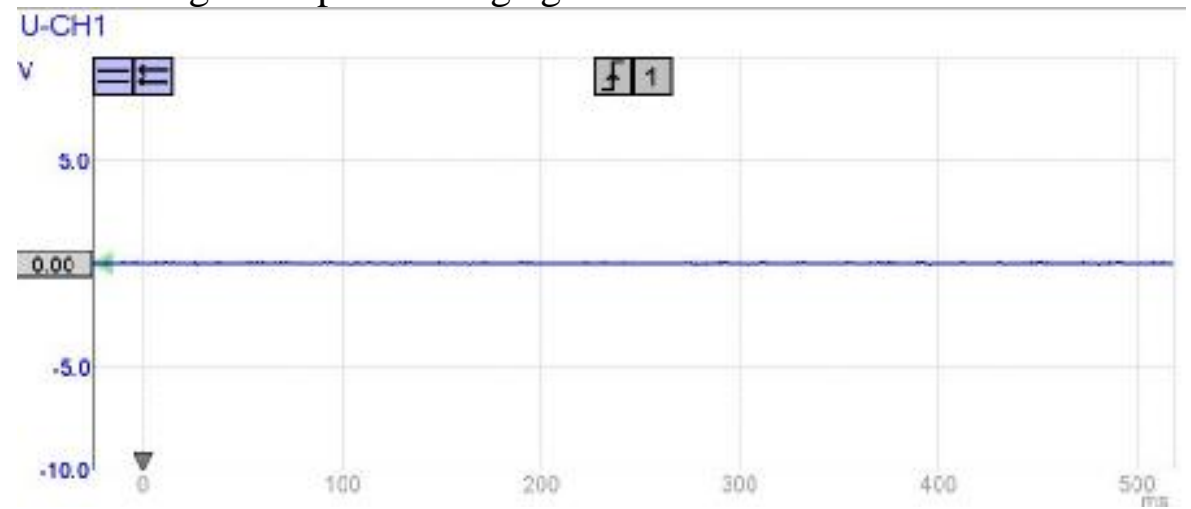

Fig. 6 the secondary ignition oscillogram of ignition coil signal line circuit breaker

\section{exchange two cylinder signal line fault diagnosis and signal waveform test}

It exchange ignition coil N127 T4ag/2 (2 cylinder signal input line) and N291T4ah/2(3 cylinder signal input line), we can be observed trembling on engine block and exhaust pipe with guns. Read fault code P0300, P0302, P0303; random / multi cylinder misfire detection,2cylinder misfire detection,3 cylinder misfire detection. When misfire counter acting, data blocks 14,15,16 group shows in a total of 612 times, 2 cylinder misfire of 307 times, 3cylinder misfire of 305 times. There is a comparison waveform between 2 cylinder ignition signal and camshaft position sensor waveform. From the Figure 7, above is the ignition signal, below is the camshaft position signal. 2 cylinder ignition signal generated at the 3cylinder ignition moment. From the Figure 8, 3 cylinder ignition signal generated at the 2 cylinder ignition moment. Therefore the Judgement is exchange between 2 and 3 cylinder ignition signal line.

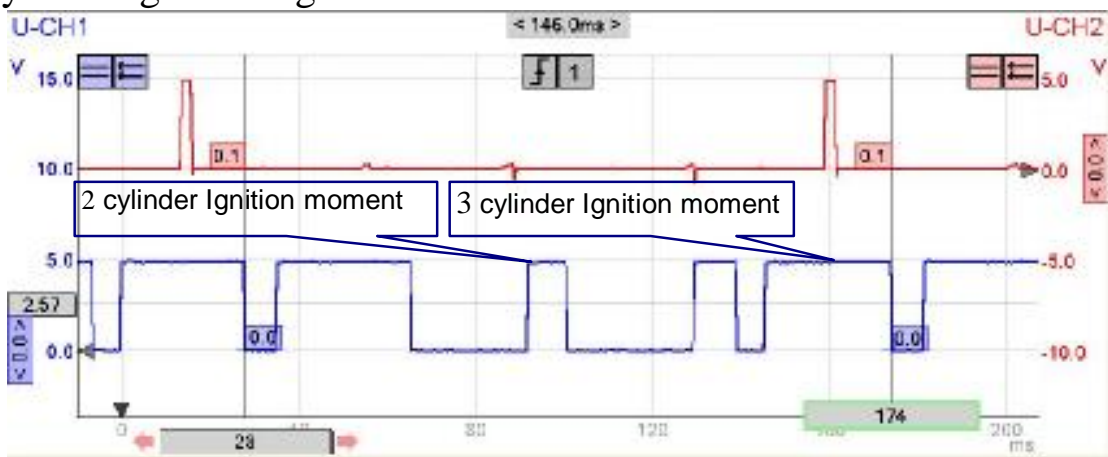

Fig. 7 the comparison waveform between 2 cylinder ignition signal and the camshaft signal

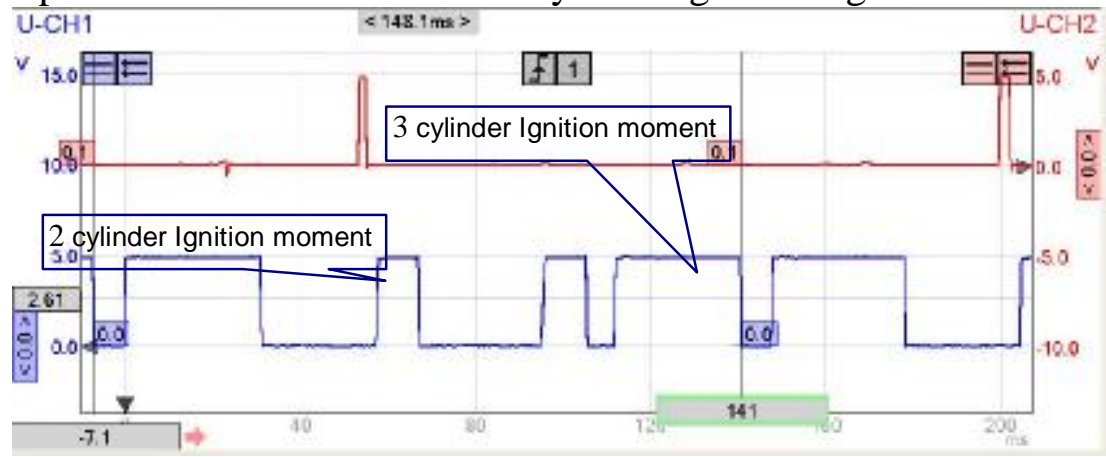

Fig. 8 the comparison waveform between 3 cylinder ignition signal and the camshaft signal

Ignition coil power supply ground line circuit breaker fault diagnosis

If ignition coil N70 T4af/4 (power supply ground line) is open, As a result of the ignition coil ground through the spark plug metal shell,there is not fault phenomenon. 


\section{Conclusion}

Single cylinder independent ignition has obvious advantage in high performance engine.The later small displacement engine have been gradually adopted this technology. Because the line concealment and diversity of fault reasons, there are still some fault that can not accurately find and eliminate by the corresponding detection device. Auto technical personnel should be test single cylinder ignition system, through the analysis of basic structure, signal transmission principle and flexible application of various means. Then we can find fault from the source by the inherent logic.

\section{Summary}

Sichuan Province Colleges -enterprise United Automobile Diagnosis and detection application technology innovation base projects ( Sichuan Provincial Department of Education (2012) )

\section{References}

[1] Peng Guangping, Li Yongxian. Fuzzy neural network in fault diagnosis of automobile engine electronic ignition system application. automotive technology,2011(3):47-50.

[2] Fang minghuang, Tang Buyan. Petrol engine secondary standard analysis of ignition waveform . Automotive practical technology,2011(8):5-7.

[3] Li Yuanfu. gasoline engine ignition module principle and maintenance methods . Hunan agriculture machinery,2011(3):104-104.

[4] Cui Huifeng, Zou Bowen, Li Jingbo. The direct-injection CNG engine ignition advance characteristic analysis . vehicle engine,2011(2):60-63.

[5] Liu Yaqin. engine ignition coil reliability analysis . mechanical engineers,2010(8):153-153.

[6] Meng Bingchen. electronical controll gasoline injection engine ignition waveform detection and research. Shandong traffic science and technology,2009(3):140-143.

[7] Zhang Hongguang, Wang Daojing, Liu Kai. automotive electronic control engine ignition energy control and test. Agricultural machinery Journal,2009(12) :19-22.

[8] Jiang Shuxia, Deng Haiying. Based on fast Fu Liye transform engine ignition waveform analysis. Central South University of Forestry and Technology Journal : Natural Science Edition,2007(27):118-121.

[9] Wang Hongwei, Xue Huimin .Bora 1.8T independent ignition coil testing method. Automotive technology,2006(3):44-46.

[10] Tan Benzhong. auto waveform and data blocks analysis. mechanical industry press,2009(1):63-82.

[11] FAW-Volkswagen training manual,2010 